\title{
Host Cell Invasion by Medically Important Fungi
}

\author{
Donald C. Sheppard ${ }^{1}$ and Scott G. Filler ${ }^{2,3}$ \\ ${ }^{1}$ Departments of Microbiology and Immunology and Medicine, McGill University, Montreal, \\ Quebec H3A 2B4, Canada \\ ${ }^{2}$ Los Angeles Biomedical Research Institute at Harbor-UCLA Medical Center, Torrance, California 90502 \\ ${ }^{3}$ David Geffen School of Medicine at UCLA, Los Angeles, California 90025 \\ Correspondence: sfiller@ucla.edu
}

To infect the host and cause disease, many medically important fungi invade normally nonphagocytic host cells, such as endothelial cells and epithelial cells. Host cell invasion is a two-step process consisting of adherence followed by invasion. There are two general mechanisms of host cell invasion, induced endocytosis and active penetration. Furthermore, fungi can traverse epithelial or endothelial cell barriers either by proteolytic degradation of intercellular tight junctions or via a Trojan horse mechanism in which they are transported by leukocytes. Although these mechanisms of host cell invasion have been best studied using Candida albicans and Cryptococcus neoformans, it is probable that other invasive fungi also use one or more of these mechanisms to invade host cells. Identification of these invasion mechanisms holds promise to facilitate the development of new approaches to inhibit fungal invasion and thereby prevent disease.

$T^{\mathrm{h}}$ he invasion of normally nonphagocytic host cells frequently plays a key role in the pathogenesis of fungal infections. Invasion provides a mechanism for the organism to traverse natural cellular barriers such as vascular endothelium or pulmonary epithelium. Invasion into endothelial or epithelial cells also benefits the fungus by concealing it from professional phagocytes, such as neutrophils and macrophages. In addition, the invaded host cell may serve as a source of nutrients for the fungus. Although it has been known for many years that pathogenic fungi invade normally nonphagocytic host cells, the molecular mechanisms by which these organisms gain entry into such host cells have only been elucidated within the past decade. A com- mon finding is that host cell invasion is a twostep process-adherence to the host cell, followed by invasion. Distinct fungal and host cell factors are usually involved in each of these two steps. This review focuses on summarizing the invasion mechanisms for medically relevant fungi.

\section{Candida SPECIES}

\section{Epithelial Cells}

Although multiple Candida species grow as part of the normal flora on skin and mucosal surfaces, Candida albicans accounts for $\sim 80 \%$ of superficial candidal infections (Redding et al.

Editors: Arturo Casadevall, Aaron P. Mitchell, Judith Berman, Kyung J. Kwon-Chung, John R. Perfect, and Joseph Heitman

Additional Perspectives on Human Fungal Pathogens available at www.perspectivesinmedicine.org

Copyright (C) 2015 Cold Spring Harbor Laboratory Press; all rights reserved; doi: 10.1101/cshperspect.a019687

Cite this article as Cold Spring Harb Perspect Med 2015;5:a019687 
D.C. Sheppard and S.G. Filler

1999; Willis et al. 1999; Richter et al. 2005). These infections include oropharyngeal candidiasis, esophageal candidiasis, vulvovaginal candidiasis, and cutaneous candidiasis. Intraepithelial C. albicans cells have been observed in samples from patients with each of these diseases (Montes and Wilborn 1968; Cawson and Rajasingham 1972; Garcia-Tamayo et al. 1982; Scherwitz 1982; Rajasingham et al. 1989; Reichart et al. 1995). Invasion of epithelial cells has also been observed in animal models of oropharyngeal candidiasis (Fig. 1A). In addition, epithelial cell invasion almost certainly occurs when hematogenously disseminated candidiasis is initiated by translocation of Candida species across the gastrointestinal mucosa (Krause et al. 1969). These data show that C. albicans invasion of epithelial cells is clinically relevant and have prompted intensive study into the mechanism by which this process occurs.

Adherence to host cell tissues is a prerequisite for invasion to occur. C. albicans expresses numerous glycosylphosphatidylinositol (GPI)anchored proteins on its cell surface that mediate adherence to host cells and basement membrane proteins. Many of these adhesins are members of the ALS, HWP, and IFF/HYR gene families. Orthologs of the ALS and IFF/ HYR gene families are also present in Candida dubliniensis, Candida parapsilosis, Candida guilliermondii, and Candida lusitaniae. Candida glabrata, which is more closely related to $\mathrm{Sa}$ charomyces cerevisiae, does not contain orthologs of C. albicans adhesins. Instead, it contains approximately 17 members of the EPA family of adhesins. For a thorough review of candidal adhesins, the reader is referred to de Groot et al. (2013).

C. albicans can invade epithelial cells by two different mechanisms: induced endocytosis and active penetration (Park et al. 2005; Zakikhany et al. 2007; Dalle et al. 2010; Zhu and Filler 2010; Wachtler et al. 2012). In addition, C. albicans can invade epithelial cell barriers by a paracellular route that involves the proteolytic digestion of tight junctions (Frank and Hostetter 2007; Villar et al. 2007; Rollenhagen et al. 2009). Induced endocytosis occurs when invasin proteins on the $C$. albicans surface bind to
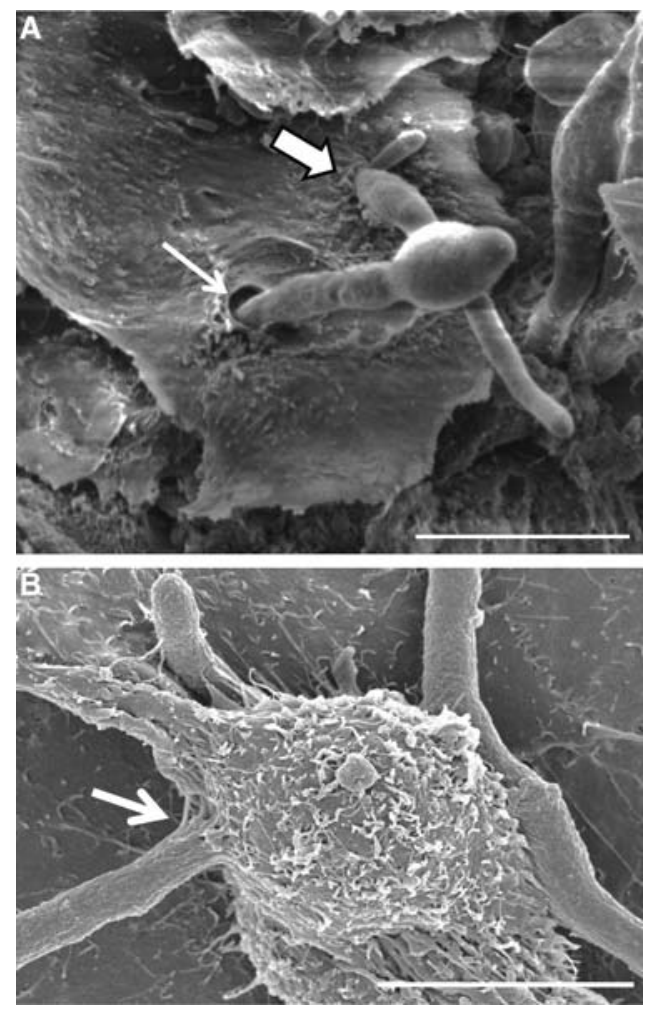

Figure 1. Invasion of epithelial cells by C. albicans and Aspergillus fumigatus. Scanning electron micrograph of $(A)$ C. albicans invasion of the epithelial cells on the dorsum of the tongue of a cortisone acetate-treated mouse with oropharyngeal candidiasis. Thick arrow indicates a hypha that is likely invading by induced endocytosis, which is characterized by ruffling of the epithelial cell plasma membrane at the site of invasion. Thin arrow indicates a hypha that is probably invading by active penetration. Note the absence of membrane ruffling at the invasion site. (Image courtesy of Dr. Mary Ann Jabra-Rizk, University of Maryland.) (B) A. fumigatus invasion of A549 pulmonary epithelial cells. Arrow indicates a hypha penetrating the epithelial cell surface, likely by induced endocytosis. Scale bars, $10 \mu \mathrm{m}$.

receptors on the surface of the epithelial cell. Binding to these receptors triggers the rearrangement of epithelial cell microfilaments, leading to the formation of pseudopods that surround the organism and pull it into the epithelial cell. To date, two C. albicans invasins that mediate induced endocytosis have been identified. The first is Als3, which is encoded by a 
member of the ALS gene family. The second is Ssa1, which is a member of the HSP70 family of heat shock proteins (Phan et al. 2007; Sun et al. 2010). The epithelial cell receptors for both of these invasins include E-cadherin and a heterodimer consisting of the epidermal growth factor receptor (EGFR) and HER2 (Phan et al. 2007; Zhu et al. 2012). Interestingly, C. albicans Als3 shares structural similarity to the internalin A (InlA) invasin of Listeria monocytogenes, which also binds with E-cadherin (Mengaud et al. 1996; Phan et al. 2007). The interaction of either InlA or Als3 to E-cadherin induces endocytosis by activating the clathrin pathway. Additional components of this pathway that are required for efficient endocytosis of $C$. albicans include dynamin and cortactin (Moreno-Ruiz et al. 2009). Whether the interaction of C. albicans with EGFR-HER2 also induces endocytosis via the clathrin-dependent pathway is not yet known.

Studies with the corticosteroid-treated mouse model of oropharyngeal candidiasis (Kamai et al. 2001; Solis and Filler 2012) indicate that induced endocytosis is important for the pathogenesis of oropharyngeal candidiasis. For example, als $3 \Delta / \Delta$ and ssa $1 \Delta / \Delta$ deletion mutants, which are poorly endocytosed by oral epithelial cells in vitro, have attenuated virulence in this model (Sun et al. 2010; Fanning et al. 2012). Furthermore, treatment of mice with GW2974, a dual inhibitor of EGFR and HER2 kinases, significantly reduces oral fungal burden during oropharyngeal candidiasis (Zhu et al. 2012). One caveat to these studies is that, although mice infected with either the als $3 \Delta / \Delta$ or ssa $1 \Delta / \Delta$ mutants, or treated with GW2974 have reduced oral fungal burden, they still have some residual disease. This result suggests that additional fungal invasins and host cell receptors may induce epithelial cell endocytosis during oropharyngeal candidiasis. Another possibility is that C. albicans invades epithelial cells by an additional mechanism, such as by active penetration.

Active penetration of host cells occurs when yeast-phase $C$. albicans cells germinate to form hyphae, which then push their way into host cells as they progressively elongate. This mech- anism of invasion can be detected in vitro by treating epithelial cells with the microfilament inhibitor, cytochalasin $\mathrm{D}$, which blocks induced endocytosis. Thus, any fungal cell that can invade epithelial cells treated with cytochalasin $\mathrm{D}$ is presumed to have invaded via active penetration (Dalle et al. 2010). C. albicans invades the TR-146 oral epithelial cell line by both induced endocytosis and active penetration. However, it invades the Caco-2 enterocyte cell line mainly by active penetration, suggesting that $C$. albicans may invade host cells at different mucosal sites by different mechanisms (Dalle et al. 2010). These intriguing in vitro findings await verification by in vivo studies.

One approach to dissect the relative importance of induced endocytosis versus active penetration in experimental animal models would be to analyze the virulence of $C$. albicans mutants that are defective in just one of these processes. However, there is substantial overlap among the $C$. albicans gene products that are required for induced endocytosis versus active penetration. For example, mutants of C. albicans that are defective in hyphal formation are unable to invade by active penetration. However, both the Als3 and Ssa1 invasins are expressed either exclusively or predominantly on the surface of hyphae (Hoyer et al. 1998; Sun et al. 2010). As a result, hyphal-deficient mutants do not express these invasins, and are therefore defective in both induced endocytosis and active penetration. This defect in two different host cell invasion mechanisms is the likely explanation for the profound virulence attenuation of the hyphal-deficient C. albicans mutant that lacks the Efg1 transcription factor (Park et al. 2005). On the other hand, although the als $3 \Delta / \Delta$ mutant forms normal length hyphae, it is defective in both induced endocytosis and active penetration in vitro (Phan et al. 2007; Wachtler et al. 2012). It is postulated that Als3 is required for active penetration because it helps anchor the C. albicans cell to the epithelial cell. Based on these in vitro data, one would expect the als3 $\Delta / \Delta$ mutant to have highly attenuated virulence in the mouse model of oropharyngeal candidiasis. Unexpectedly, this mutant has only modestly attenuated virulence that is 
only detectable during the early stages of oropharyngeal infection (Fanning et al. 2012). Although the exact explanation for the mild attenuation in virulence of the als $3 \Delta / \Delta$ mutant is unknown, it is probable that functional redundancy of additional adhesins and invasins compensates for the absence of Als3. Nevertheless, the discrepancy between in vitro and in vivo results shows the importance of verifying in vitro data in biologically relevant animal models of infection.

During mucosal candidiasis, C. albicans also can invade the superficial epithelium by passing between epithelial cells. This paracellular invasion occurs when C. albicans secreted aspartyl proteinases degrade E-cadherin, which is a component of the tight junctions between epithelial cells (Frank and Hostetter 2007; Villar et al. 2007; Rollenhagen et al. 2009). Importantly, biopsies from patients show that epithelial cell E-cadherin expression is decreased when oropharyngeal candidiasis is present and returns to normal when the infection is treated (Fidel 2006; Quimby et al. 2012). These data suggest that C. albicans-induced degradation of E-cadherin is clinically relevant.

\section{Endothelial Cells}

During the initiation of hematogenously disseminated candidiasis, blood-borne Candida spp. must cross the endothelial cell lining of the blood vessels to invade the deep tissues (Grubb et al. 2008). In vitro, C. albicans can invade endothelial cells by induced endocytosis and active penetration (Rotrosen et al. 1985; Filler et al. 1995). However, virtually all studies of endothelial cell invasion have focused on the process of induced endocytosis. Furthermore, some species of Candida, such as C. glabrata and C. parapsilosis do not form hyphae in vivo and therefore cannot invade endothelial cells via active penetration.

The C. albicans invasins, Als3 and Ssa1, induce fungal endocytosis by human endothelial cells from multiple different vascular beds, including umbilical vein endothelial cells, dermal microvascular endothelial cells, and brain microvascular endothelial cells (Phan et al. 2007;
Sun et al. 2010; Liu et al. 2011; Seidl et al. 2012). $\mathrm{Als} 3$ and Ssa1 induce endocytosis by interacting with $\mathrm{N}$-cadherin on umbilical vein endothelial cells (Phan et al. 2007; Sun et al. 2010). Furthermore, additional endothelial cell receptors for C. albicans must exist because siRNA (small interfering RNA) knockdown of N-cadherin only partially inhibits the endocytosis of this organism. Maximal endocytosis of C. albicans requires the presence of septin 7, a small intracellular GTP-binding protein that forms a complex with $\mathrm{N}$-cadherin and functions as a link between it and actin microfilaments. Septin 7 is necessary for $\mathrm{N}$-cadherin to accumulate around C. albicans cells and induce endocytosis (Phan et al. 2013). The accumulation of $\mathrm{N}$-cadherin around C. albicans triggers endocytosis via the clathrin uptake pathway (Moreno-Ruiz et al. 2009). It is probable that the neural WiskottAldrich syndrome protein (N-WASP) is also involved in the rearrangement of endothelial cell microfilaments during the endocytosis of C. albicans (Shintaku et al. 2013).

The endothelial cells that line the cerebral blood vessels are unique in that they form tight junctions and express certain proteins on their surface that are not expressed by endothelial cells from other vascular beds. One of these proteins is gp96, a member of the heat shock protein family. C. albicans Als3 interacts with surfaceexpressed gp96 on brain microvascular endothelial cells in vitro, leading to the endocytosis of the organism (Liu et al. 2011). Importantly, siRNA knockdown of gp96 inhibits the endocytosis of C. albicans by brain microvascular endothelial cells, but not human umbilical vein endothelial cells. These results indicate that $C$. albicans uses different host cell receptors to invade endothelial cells of different vascular beds.

The role of Als3 in mediating invasion of brain endothelial cells during disseminated infection was discovered during the analysis of a C. albicans $v p s 51 \Delta / \Delta$ mutant, which is defective in retrograde protein trafficking (Liu et al. 2011, 2014). This mutant has increased surface expression of Als3 and enhanced capacity to invade brain microvascular endothelial cells in vitro. In addition, when injected intravenously into mice, the $v p s 51 \Delta / \Delta$ mutant has increased 
trafficking to the brain. This trafficking is partially dependent on Als3 because deletion of both copies of $A L S 3$ in the $v p s 51 \Delta / \Delta$ mutant reduces its capacity to infect the brain (Liu et al. 2011). Recently, a $C$. albicans slr $1 \Delta / \Delta$ mutant was found to have increased trafficking to the brain following intravenous inoculation into mice, and this mutant also has increased surface expression of Als3 (Ariyachet et al. 2013). Furthermore, a strain of C. glabrata that was engineered to heterologously express $C$. albicans Als3 also has increased trafficking to the brain in the mouse model of disseminated infection (Fu et al. 2013). Collectively, these data indicate that C. albicans Als3 mediates binding to receptors, such as gp96, that are expressed specifically on the surface of brain endothelial cells. Moreover, it is known that endothelial cells of other organs also express unique profiles of surface proteins (Nolan et al. 2013). Therefore, it is likely that $C$. albicans binds to different endothelial cell receptors when it invades different organs.

Currently, C. albicans causes $\sim 50 \%$ of cases of disseminated candidiasis; the majority of the remaining cases are caused by C. glabrata and C. parapsilosis (Pfaller et al. 2012). Although the mechanisms by which C. glabrata invades endothelial cells is not currently known, it has recently been discovered that $C$. parapsilosis invades human umbilical vein endothelial cells by the process of induced endocytosis (Shintaku et al. 2013). This mechanism of invasion requires endothelial cell N-WASP and intact endothelial cell microfilaments. Furthermore, the endocytosed organisms localize to an acidified subcompartment within the endothelial cell (Shintaku et al. 2013). The endothelial cell receptor(s) and C. parapsilosis invasin(s) that mediate endocytosis have not yet been discovered. However, the $C$. parapsilosis genome contains five ALS orthologs (Butler et al. 2009), and it is tempting to speculate that the product of at least one of these orthologs may function similarly to C. albicans Als3.

\section{A. fumigatus}

Invasive aspergillosis is the most common invasive mold infection of humans, with the species
A. fumigatus accounting for the majority of these infections (reviewed in Abad et al. 2010). Both conidia and hyphae of $A$. fumigatus interact with a number of pulmonary cell types during different stages of invasive aspergillosis. Following inhalation, conidia that escape macrophage phagocytosis and killing can rapidly and avidly adhere to pulmonary alveolar epithelial cells and basement membrane components (Bromley and Donaldson 1996; DeHart et al. 1997; Paris et al. 1997; Wasylnka and Moore 2002). These adherent organisms invade alveolar epithelial cells by the process of induced endocytosis. Alveolar epithelial cells endocytose approximately one-third of adherent conidia through the formation of pseudopods followed by membrane invagination and internalization (Paris et al. 1997; Wasylnka and Moore 2002). The endocytosed conidia are initially contained within acidic phagosomes where they are killed (Paris et al. 1997; Wasylnka and Moore 2003). However, a subset of these endocytosed conidia can germinate and escape this compartment to produce hyphae, which then exit the cell into the extracellular space (Wasylnka et al. 2005). In addition, adherent extracellular conidia also germinate to produce hyphae, which in turn can invade neighboring epithelial cells (Fig. 1B), possibly via active penetration (Wasylnka and Moore 2002). Thus, both conidia and hyphae of $A$. fumigatus can adhere to and invade epithelial cells during the course of infection.

Following infection and invasion of epithelial cells, hyphae can penetrate more deeply into pulmonary tissues and invade pulmonary vascular endothelial cells (Lopes-Bezerra and Filler 2004; Kamai et al. 2009). After invading endothelial cells from their abluminal side, hyphae can then traverse the cell to gain access to the vascular compartment (Kamai et al. 2009). Once in the vascular compartment, hyphal fragments can disseminate to distal sites where they are believed to adhere to and invade vascular endothelial cells from the luminal side before penetrating further into other deep tissues such as the brain (Filler and Sheppard 2006). Invasion of the abluminal and luminal surfaces of endothelial cells by hyphae differs in several 
respects. During luminal infection, hyphal invasion is associated with the formation of membrane pseudopods and dense actin polymerization surrounding the intracellular hyphae (Lopes-Bezerra and Filler 2004; Kamai et al. 2009). In contrast, during abluminal infections, endothelial pseudopods are not formed, and the degree of actin polymerization around invading hyphae is significantly lower and more loosely organized, suggesting that invasion may be occurring via active penetration (Kamai et al. 2009). These results suggest that although luminal infection may occur through induced endocytosis, abluminal infection of endothelial cells may represent active penetration, or a form of phagocytosis analogous to $\mathrm{CD} 11 \mathrm{~b} / \mathrm{CD} 18$ driven phagocytosis in macrophages in which complement coated zymosan particles are incorporated into membrane pits (Kamai et al. 2009).

\section{Molecular Mechanisms of Aspergillus Adherence to Host Cells}

The fungal factors mediating the adherence of conidia to pulmonary cells remain largely unknown. Resting conidia are highly hydrophobic because of the presence of an organized layer of rodlet proteins (Paris et al. 2003). Deletion of the gene encoding these proteins ( $\operatorname{rod} A)$ reduces adherence of conidia to the basement membrane component collagen but does not alter adherence to other substrates such as laminin, fibronectin, or the A549 pulmonary epithelial cell line (Thau et al. 1994). Similarly, RodA-deficient conidia display normal virulence in a mouse model of invasive aspergillosis, suggesting that hydrophobins are dispensable for adherence of conidia in vivo (Thau et al. 1994).

A. fumigatus conidia have also been reported to have a higher abundance of negatively charged sialic acid residues on their surface than other less pathogenic Aspergillus species (Wasylnka et al. 2001). The abundance of sialic acid residues on the surface of conidia among these species correlates with their adherence to basal lamina components. Removal of these residues by sialidase treatment reduces the binding of conidia to poly-L-lysine. Also, a sialyated glycoprotein competitively inhibits binding of
A. fumigatus conidia to fibronectin, suggesting a role for these residues in adhesion of conidia. The role of sialic acid-mediated adherence of conidia in the pathogenesis of invasive aspergillus remains untested in vivo.

In contrast to what has been found with $C$. albicans, GPI-anchored cell wall proteins have not been found to play a major role in mediating the adherence of A. fumigatus conidia or hyphae to host cells during infection. Attempts to identify cell wall proteins with a role in host pathogen interactions have identified a number of candidate adhesins including CspA (Levdansky et al. 2010), CfmA-C (Vaknin et al. 2013), and CalA (Upadhyay et al. 2009). Deletion of CspA or CfmA-C resulted in alterations in cell wall architecture and composition but did not affect host cell adherence or virulence, suggesting that these proteins play more of a structural role within the cell wall (Levdansky et al. 2010; Vaknin et al. 2013). Recombinant CalA was found to bind to laminin in vitro (Upadhyay et al. 2009); however, a mutant deficient in CalA has not been tested for alterations in host cell binding or virulence, and thus the importance of this protein in host-pathogen interactions remains unknown.

Recently, the secreted and cell wall associated exopolysaccharide galactosaminogalactan (GAG) has been found to play a major role in mediating adherence of hyphae to basement membrane macromolecules as well as endothelial and epithelial cells (Gravelat et al. 2010, 2013; Lee et al. 2013). GAG is a heteroglycan composed of variable amounts of galactose and $N$-acetyl-galactosamine (GalNAc), which is found in the outer layer of the cell wall as well as within the interstitial matrix of fungal biofilms in vitro and in vivo (Loussert et al. 2010; Fontaine et al. 2011). GAG is produced by hyphae and is not present on conidia (Fontaine et al. 2011). The mechanism by which GAG mediates host cell adherence is not fully understood, but adhesion is likely mediated by the GalNAc component of this glycan. Mutant strains expressing GalNAc-poor GAG are less adherent to host cells, whereas those expressing galactose-poor GAG retain normal adherence to host cells and macromolecules. Furthermore, as 
a result of the poor adherence of GAG-deficient mutants to host cells, these mutants are also defective in invading and damaging these cells (Gravelat et al. 2013; Lee et al. 2013); the epithelial or endothelial cell receptors to which GAG binds are not known. In addition to mediating adherence, GAG also suppresses inflammation by several mechanisms. GAG on the surface of hyphae conceals $\beta$-glucan from recognition by the pattern-recognition receptor dectin-1 on leukocytes much in the same way that hydrophobins conceal $\beta$-glucan in resting conidia (Gravelat et al. 2013). Further, GAG can directly induce leukocyte apoptosis via an uncharacterized mechanism, and administration of GAG to mice worsens outcomes during experimental infection with A. fumigatus (Fontaine et al. 2011; Lee et al. 2013). Strains deficient in GAG are hypovirulent (Gravelat et al. 2010, 2013), although the relative contribution of GAG-mediated adherence and immunosuppression to virulence is undefined and the subject of ongoing study.

\section{Molecular Mechanisms of Aspergillus Invasion of Host Cells}

The molecular mechanisms by which A. fumigatus conidia and hyphae invade nonphagocytic host cells have not been studied to the same extent as with C. albicans. A handful of studies have examined the pathways involved in conidial endocytosis by epithelial and endothelial cells. As with C. albicans, cadherins have been implicated in the invasion of both epithelial and endothelial cells by A. fumigatus. Endocytosis of hyphae by human umbilical vein endothelial cells was reduced by treatment with antibodies to $\mathrm{N}$-cadherin, and endocytosis of A. fumigatus conidia by pulmonary epithelial cells was reduced by antibodies or siRNA directed to E-cadherin (Xu et al. 2010, 2012). The fungal factors bound by cadherins and the role of cadherin binding in the pathogenesis of invasive aspergillosis have not yet been elucidated. Identifying the A. fumigatus ligands that interact with cadherins will be of particular interest because no homolog of C. albicans Als3 has been identified in A. fumigatus.
A single study has identified a role for phospholipase D (PLD) signaling in the endocytosis of germinating conidia by pulmonary epithelial cells. Exposure of $\beta-1,3$ - glucans on the surface of germinating conidia was found to induce the activation of phospholipase D via a dectin-1dependent mechanism. Inhibition of this interaction with antidectin-1 antibodies, chemical inhibitors of PLD, or anti-PLD siRNA reduced the number of conidia endocytosed by epithelial cells. Interestingly, PLD was found to colocalize with endocytosed conidia, suggesting that PLD may play a role in endosomal processing or maturation in addition to early endocytic events (Han et al. 2011). Aside from $\beta$-1,3-glucans, no other fungal ligands that mediate invasion have been identified in A. fumigatus, and this area should be a priority for future research.

\section{Cryptococcus neoformans}

When C. neoformans cells are inhaled by a susceptible host, a pulmonary infection can develop that is often asymptomatic. Subsequently, the organism is carried by the bloodstream from the lungs to the brain, where it crosses the blood-brain barrier and causes a chronic meningitis. To initiate a pulmonary infection, $C$. neoformans must adhere to and invade the epithelial lining of the airways or alveoli. Recently, the first C. neoformans adhesin, Cfl1, was discovered (Wang et al. 2012). This protein is secreted by the organism and it induces flocculation of C. neoformans cells. It is also required for normal hyphal formation. Interestingly, when Cfl1 is shed from the fungal cell surface, it signals adjacent cells to up-regulate Cfll production (Wang et al. 2013). Whether Cfl1 mediates adherence to host cells is not yet known, but a strain that overexpresses CFL1 has attenuated virulence, probably because increased flocculation of the fungal cells prevents dissemination (Wang et al. 2012).

After $C$. neoformans adheres to host cells, it must invade them to cause disease. Although C. neoformans can invade the A549 pulmonary epithelial cell line via induced endocytosis in vitro (Barbosa et al. 2007), the molecular mechanisms governing this process are not yet known. 
In contrast, the invasion of C. neoformans across the endothelial cells that form the bloodbrain barrier has been investigated extensively. It has been found that $C$. neoformans can cross brain endothelial cells by three different mechanisms: proteolytic degradation of tight junctions, induced endocytosis, and macrophage transport. The capacity of $C$. neoformans to directly invade the endothelial cell lining of cerebral blood vessels in vivo has been shown by experiments in which live organisms were injected intravenously into mice. Studies in which the infected brains were examined by histopathology showed the presence of $C$. neoformans cells either within or between the cerebral endothelial cells, indicating that the organism was crossing the blood-brain barrier by either a transcellular or paracellular route (Chretien et al. 2002; Chang et al. 2004). Using intravital imaging of live mice that had been injected with fluorescently labeled C. neoformans, it was observed that, although both live and killed organisms lodged in the cerebral capillaries, only live organisms were able to traverse endothelial cells and invade the brain (Shi et al. 2010). Moreover, a ure $1 \Delta$ mutant that did not produce urease was defective in crossing the cerebral endothelial cells. Mice infected with this mutant or treated with the urease inhibitor, flurofamide, had an approximate 1- to 2-day increase in median survival and a threefold reduction in brain fungal burden. Similarly, another group found that mice inoculated intravenously with the urease-deficient ure $1 \Delta$, ure $7 \Delta$, or nic1 $\Delta$ mutants had a twofold reduction in brain fungal burden after $24 \mathrm{~h}$ of infection (Singh et al. 2013). Importantly, the brain fungal burden of mice injected intracerebrally with the ure $1 \Delta$ mutant was similar to that of mice infected with the wild-type strain, indicating that, although urease is required for maximal brain invasion, it is not required for the organism to grow once it has entered the brain (Olszewski et al. 2004).

Urease likely facilitates $C$. neoformans passage between brain endothelial cells by degrading their intercellular tight junctions. Incubation of human brain microvascular endothelial cells with wild-type $C$. neoformans, but not the ure $1 \Delta$ mutant, induces degradation of the ZO-1 junctional protein in vitro (Singh et al. 2013). In vitro data indicate that $C$. neoformans can also disrupt tight junctions between endothelial cells by a second mechanism. When viable organisms are exposed to plasma, they are coated with plasminogen. As these coated organisms come into contact with brain endothelial cells, they induce endothelial cell urokinase activity, which converts the plasminogen to plasmin. The plasmin serine protease then degrades endothelial cell tight junctions and facilitates paracellular invasion (Stie and Fox 2012a,b). Although this mechanism of translocation has been clearly shown to occur with bovine brain endothelial cells in vitro, it has not yet been investigated in a relevant animal model of cryptococcal meningitis. Thus, its biological significance remains unclear.

In vitro studies have also shown that $C$. neoformans can invade brain endothelial cells by inducing its own endocytosis. Endocytosis is triggered when hyaluronic acid in the C. neoformans capsule binds to the CD44 hyaluronic acid receptor on the surface of brain endothelial cells (Jong et al. 2007, 2008b). CD44 is located in plasma membrane lipid rafts on the endothelial cell surface (Long et al. 2012). Binding of $C$. neoformans hyaluronic acid to CD44 activates the protein kinase $\mathrm{C}(\mathrm{PKC})$ - $\alpha$ signaling pathway, of which the dual specificity tyrosine phosphorylation-regulated kinase 3 (DYRK3) is an additional component (Jong et al. 2008a; Huang et al. 2011). Activation of this pathway results in rearrangement of endothelial cell actin microfilaments and the formation of pseudopods that engulf the organism and draw it into the endothelial cell.

The role of hyaluronic acid and CD44 in C. neoformans invasion of the brain has been investigated in vivo. Hylaronic acid is synthesized by the Cps1 hyaluronic acid synthase, and a $\operatorname{cps} 1 \Delta$ mutant has reduced capacity to invade brain endothelial cells in vitro (Chang et al. 2006; Jong et al. 2007). In addition, this mutant has dramatically attenuated virulence following intravenous inoculation into mice. However, because the cps1 $1 \Delta$ mutant grows slowly at $37^{\circ} \mathrm{C}$ (Chang et al. 2006), it is probable that some of its attenuation in virulence is be- 
cause of temperature sensitivity as well as impaired brain invasion. The brain contains high levels of inositol and this sugar also affects the hyaluronic acid content of the $C$. neoformans capsule. Exposure of $C$. neoformans to physiologic levels of inositol increases CPS1 mRNA levels, enhances the hyaluronic acid content of the capsule, and stimulates transcytosis across human brain microvascular endothelial cells in vitro. Moreover, an $i \operatorname{tr} 1 a \Delta i \operatorname{tr} 3 c \Delta$ double mutant that lacks the two major inositol transporters has impaired endothelial cell transcytosis in vitro and attenuated virulence in mice. Of note, this mutant had a greater defect in infecting the brain than the lung, suggesting that inositol uptake from the host is particularly important for brain invasion (Wang et al. 2011; Liu et al. 2013).

The contribution of the hyaluronic acidCD44 interaction to brain invasion has also been investigated using $\mathrm{CD}_{4} 4^{-/}$knockout mice. When infected intravenously with wildtype $C$. neoformans, these mice have a modest increase in survival and roughly a twofold reduction in brain and cerebral spinal fluid fungal burden (Jong et al. 2012). One reason that these mice are not more resistant to $C$. neoformans brain invasion may be that the organism invades the brain by additional mechanisms, such as via the paracellular route. Also, there is a second receptor for hyaluronic acid on brain endothelial cells, receptor of hyaluronan-mediated motility (RHAMM). Indeed, siRNA knockdown of both CD44 and RHAMM results in an additive reduction of brain microvascular endothelial cell invasion in vitro (Jong et al. 2012). Moreover, both CD44 and RHAMM are associated with lipid rafts. Treatment of mice with simvastatin, which disrupts lipid rafts, ameliorates cryptococcal meningitis, reducing brain fungal burden by about sixfold (Jong et al. 2012). Although it is possible that simvastatin also affects some virulence attributes of C. neoformans, these data suggest that the binding of hyaluronic acid to its endothelial cell receptors plays a key role in the capacity of $C$. neoformans to transcytose across the blood-brain barrier in vivo.

A final way that $C$. neoformans can invade the brain is via a Trojan horse mechanism, whereby the organism is phagocytosed by a monocyte, which then diapedeses across the blood-brain barrier into the brain, transporting the fungus with it. This mechanism of invasion has been shown experimentally by infecting mice intravenously with bone marrowderived monocytes that had been infected in vitro with $C$. neoformans. Mice infected with C. neoformans within monocytes had a 3.9fold higher brain fungal burden compared with mice infected with free organisms. Interestingly, the mice infected with $C$. neoformans within monocytes also had increased number of organisms in the spleen and lung, suggesting that the Trojan horse mechanism facilitates invasion of these organs as well. Also, depleting phagocytes by injecting the mice with clodronate caused at least a $40 \%$ reduction in the fungal burden of the brain, spleen, and lung when the animals were subsequently inoculated with free C. neoformans (Charlier et al. 2009). Collectively, these results indicate that $C$. neoformans can cross the blood-brain barrier by the Trojan horse mechanism. The ability of this organism to traverse brain endothelial cells by at least three different mechanisms is the likely reason why blocking any single mechanism causes only a partial reduction in brain fungal burden in the animal model.

\section{MUCORALES}

Fungi of the order Mucorales, especially Rhizopus oryzae, can cause mucormycosis. This disease is usually initiated in susceptible hosts by inhalation of conidia or by contamination of wounds. Patients who are receiving cancer chemotherapy or are in diabetic ketoacidosis are at particular risk for developing mucormycosis. This disease most commonly involves the paranasal sinuses, but it can also involve the lung and other organs. How these fungi invade epithelial cell barriers to cause infection is not currently known. However, a hallmark of mucormycosis is invasion of the blood vessels, a process that results in intravascular thrombosis and tissue infarction. Recently, it has been discovered that $R$. oryzae invades endothelial cells by induced endocytosis. This process is initiated 
when the $\mathrm{CotH} 2$ and $\mathrm{CotH} 3$ invasins expressed on the surface of the hyphae bind to GRP78, a member of the HSP70 heat shock protein family that is expressed on the surface of endothelial cells. Knockdown of $\mathrm{CotH}$ in $R$. oryzae by siRNA or treatment with an anti-CotH antiserum inhibits the capacity of this organism to invade human umbilical vein endothelial cells in vitro. Similarly, shRNA knockdown of GRP78 in endothelial cells or treatment with an anti-GRP78 antiserum also significantly reduces fungal invasion of endothelial cells in vitro (Liu et al. 2010; Gebremariam et al. 2014).

The importance of the CotH-GRP78 interaction in the pathogenesis of mucormycosis has been shown in the diabetic ketoacidotic mouse model of $R$. oryzae infection. An R. oryzae mutant with siRNA knockdown of CotH expression has impaired virulence in these mice. Furthermore, treatment with polyclonal antibodies directed against either CotH or GRP78 protects mice against mucormycosis. Although these in vivo studies were performed using a clinical isolate of $R$. oryzae, orthologs of $\mathrm{CotH}$ are present in all members of the Mucorales that have been tested. In addition, several different Mucorales members bind to GRP78 in vitro. Finally, mice with diabetic ketoacidosis have increased mRNA levels of grp78 in the lungs and brain, providing a possible explanation for why the presence of diabetic ketoacidosis is a unique risk factor for mucormycosis in patients (Liu et al. 2010; Gebremariam et al. 2014). Therefore, it is likely that the induction of endocytosis via the interaction of CotH with GRP78 is a central mechanism by which Mucorales invade endothelial cells and perhaps other types of host cells.

\section{Blastomyces dermatitidis}

Infection with the dimorphic fungus $B$. dermatitidis is acquired through inhalation of conidia, which transform to yeast in the host. Following the initial pulmonary infection, $B$. dermatitidis can disseminate to cause distal skin and bone infections either acutely or late after resolution of the pulmonary disease. One fungal protein, Bad1, plays a central role in host cell adherence, invasion, and virulence of $B$. dermatitidis. Bad1, formerly known as WI-1, is secreted by the yeast form of $B$. dermatitidis, in which it re-associates with the cell wall through covalent and noncovalent interactions with chitin (Brandhorst and Klein 2000). Badl contains a tandem repeat domain that is homologous to the Yersinia invasin protein (Klein et al. 1993) and mediates adherence to pulmonary tissues. Bad1 also mediates adherence to and invasion of macrophages through binding to CD14 and CD11b/CD18 (Newman et al. 1995). Much like the A. fumigatus polysaccharide adhesin GAG, Bad1 plays an important role in virulence both as an adhesin and through mediating direct immunosuppressive effects. Mice infected with a Bad1-deficient strain mutant produce increased levels of proinflammatory cytokines such as interleukin (IL)-12, and tumor necrosis factor (TNF)- $\alpha$ and lower levels of anti-inflammatory IL-10 and transforming growth factor (TGF)- $\beta$ (Brandhorst et al. 1999; Finkel-Jimenez et al. 2002; Wuthrich et al. 2006). Thus, the improved survival of mice infected with the Bad1-deficient strain is probably because of a combination of reduced adherence and an increased host inflammatory response.

\section{Pnemocystis jirovecii}

$P$. jirovecii is an important cause of pneumonia in immunocompromised hosts, but rarely disseminates beyond the pulmonary system. Like other pathogenic fungi, $P$. jirovecii adheres well to pulmonary epithelial cells (Pottratz and Martin 1990a,b; Pottratz et al. 1991). However, this fungus does not invade these cells to any significant degree and intracellular fungi are observed only within macrophages and granulocytes (Hoyte et al. 1997; Limper et al. 1997). The adherence of $P$. jirovecii to epithelial cells is mediated through the binding of the extracellular macromolecules fibronectin and vitronectin, which serve as bridging molecules linking the fungus to host cells (Pottratz and Martin 1990b; Pottratz et al. 1991, 1994; Limper et al. 1993). Vitronectin and fibronectin both interact with $\beta$-glucans on the surface of the fungus (Vassallo et al. 2001), and fibronectin is also bound by the major surface glycoprotein (previously termed 
gp120) of $P$. jirovecii (Pottratz et al. 1991). Heterologous expression of this major surface glycoprotein in the yeast $S$. cerevisiae enhances the adherence of this organism to epithelial cells, highlighting the importance of this glycoprotein in adhesion (Kutty et al. 2013). Fibronectin immobilized on the surface of $P$. jirovecii is bound by epithelial cell $\beta$-integrins (Pottratz et al. 1994). Interestingly, the epithelial cell adherence of $P$. jirovecii induces IL-6 secretion, which in turn increases the expression of both fibronectin and $\beta$-integrins and results in augmented adherence of the organism to epithelial cells (Pottratz et al. 1998). Pneumocystis adherence is also enhanced through aggregation of organisms at the epithelial cell surface through the binding of multimeric surfactant protein $\mathrm{D}$ on the surface of the organism (Yong et al.2003). These aggregates are more resistant to macrophage phagocytosis, thus protecting the organism from host defenses.

\section{Sporothrix schenckii}

S. schenckii is a dimorphic fungus that causes a nodular lymphangitis following inoculation injury. S. schenckii binds avidly to host basement membrane constituents such as laminin and fibronectin (Lima et al. 2001, 2004). This binding is mediated by a number of poorly characterized cell glycoproteins (Teixeira et al. 2009; Sandoval-Bernal et al. 2011). Antibodies to one such glycoprotein, Gp70, as well as cell wall fractions and soluble carbohydrates, can decrease binding of $S$. schenckii to host macromolecules, suggesting that these proteins bind to host factors through a lectin-type interaction (RuizBaca et al. 2009).

Although uncommon, hematogenous dissemination of $S$. schenckii to other organs can occur, suggesting that this organism can traverse the vascular endothelium. Active endocytosis of yeast cells by human vascular endothelial cells has been observed, and is induced by the proinflammatory cytokine IL-1 $\beta$ (Figueiredo et al. 2004). In contrast, exposure of endothelial cell monolayers to TGF- $\beta$ enhances adherence of yeast to basement membrane fibronectin, and induce the transendothelial cell migration of
S. schenckii via a paracellular route (Figueiredo et al. 2007). It is not known which of these two mechanisms predominates during infection. Also, the fungal ligands and host receptors that are involved in these interactions remain undiscovered.

\section{CONCLUDING REMARKS}

Some of the key details about the mechanisms of host cell invasion by C. albicans and C. neoformans have been elucidated, whereas the invasion mechanisms of other medically important fungi are poorly understood. Data obtained with $C$. albicans and $C$. neoformans show that host cell invasion is a two-step process consisting of adherence followed by invasion. Indeed, the large number of adhesin genes present in the genomes of Candida spp. indicates the importance of adherence to host cells during colonization and initiation of disease. There are two general mechanisms of host cell invasion, induced endocytosis and active penetration. Furthermore, fungi can traverse epithelial cell or endothelial cell barriers by either proteolytic degradation of intercellular tight junctions or a Trojan horse mechanism. Both C. albicans and $C$. neoformans appear to invade host cells by multiple mechanisms; it is thus highly probable that other invasive fungi also use one or more of these mechanisms to invade host cells. Identification of these invasion mechanisms holds promise to facilitate the development of new approaches to inhibit fungal invasion and thereby prevent disease.

\section{ACKNOWLEDGMENTS}

This work is supported in part by Grants R01AI054928, R01AI073829, and R01DE017088 from the National Institutes of Health (NIH), and by Grants MOP123306 and MOP81361 from the Canadian Institutes of Health Research.

\section{REFERENCES}

Abad A, Fernandez-Molina JV, Bikandi J, Ramirez A, Margareto J, Sendino J, Hernando FL, Ponton J, Garaizar J, Rementeria A. 2010. What makes Aspergillus fumigatus a 
D.C. Sheppard and S.G. Filler

successful pathogen? Genes and molecules involved in invasive aspergillosis. Rev Iberoam Micol 27: 155-182.

Ariyachet C, Solis NV, Liu Y, Prasadarao NV, Filler SG, McBride AE. 2013. SR-like RNA-binding protein Slr1 affects Candida albicans filamentation and virulence. Infect Immun 81: 1267-1276.

Barbosa FM, Fonseca FL, Figueiredo RT, Bozza MT, Casadevall A, Nimrichter L, Rodrigues ML. 2007. Binding of glucuronoxylomannan to the CD14 receptor in human A549 alveolar cells induces interleukin-8 production. Clin Vaccine Immunol 14: 94-98.

Brandhorst T, Klein B. 2000. Cell wall biogenesis of Blastomyces dermatitidis. Evidence for a novel mechanism of cell surface localization of a virulence-associated adhesin via extracellular release and reassociation with cell wall chitin. J Biol Chem 275: 7925-7934.

Brandhorst TT, Wuthrich M, Warner T, Klein B. 1999. Targeted gene disruption reveals an adhesin indispensable for pathogenicity of Blastomyces dermatitidis. J Exp Med 189: 1207-1216.

Bromley IM, Donaldson K. 1996. Binding of Aspergillus fumigatus spores to lung epithelial cells and basement membrane proteins: Relevance to the asthmatic lung. Thorax 51: 1203-1209.

Butler G, Rasmussen MD, Lin MF, Santos MA, Sakthikumar S, Munro CA, Rheinbay E, Grabherr M, Forche A, Reedy JL, et al. 2009. Evolution of pathogenicity and sexual reproduction in eight Candida genomes. Nature 459: 657-662.

Cawson RA, Rajasingham KC. 1972. Ultrastructural features of the invasive phase of Candida albicans. Br J Dermatol 87: 435-443.

Chang YC, Stins MF, McCaffery MJ, Miller GF, Pare DR, Dam T, Paul-Satyasee M, Kim KS, Kwon-Chung KJ. 2004. Cryptococcal yeast cells invade the central nervous system via transcellular penetration of the blood-brain barrier. Infect Immun 72: 4985-4995.

Chang YC, Jong A, Huang S, Zerfas P, Kwon-Chung KJ. 2006. CPS1, a homolog of the Streptococcus pneumoniae type 3 polysaccharide synthase gene, is important for the pathobiology of Cryptococcus neoformans. Infect Immun 74: 3930-3938.

Charlier C, Nielsen K, Daou S, Brigitte M, Chretien F, Dromer F. 2009. Evidence of a role for monocytes in dissemination and brain invasion by Cryptococcus neoformans. Infect Immun 77: 120-127.

Chretien F, Lortholary O, Kansau I, Neuville S, Gray F, Dromer F. 2002. Pathogenesis of cerebral Cryptococcus neoformans infection after fungemia. J Infect Dis 186: 522-530.

Dalle F, Wachtler B, Coralie L, Holland G, Bannert N, Wilson D, Labruere C, Bonnin A, Hube B. 2010. Cellular interactions of Candida albicans with human oral epithelial cells and enterocytes. Cell Microbiol 12: 248-271.

de Groot PW, Bader O, de Boer AD, Weig M, Chauhan N. 2013. Adhesins in human fungal pathogens: Glue with plenty of stick. Eukaryot Cell 12: 470-481.

DeHart DJ, Agwu DE, Julian NC, Washburn RG. 1997. Binding and germination of Aspergillus fumigatus conidia on cultured A549 pneumocytes. J Infect Dis 175: 146150.
Fanning S, Xu W, Solis N, Woolford CA, Filler SG, Mitchell AP. 2012. Divergent targets of Candida albicans biofilm regulator Bcr1 in vitro and in vivo. Eukaryot Cell 11: 896904.

Fidel PL Jr. 2006. Candida-host interactions in HIV disease: Relationships in oropharyngeal candidiasis. Adv Dent Res 19: $80-84$.

Figueiredo CC, De Lima OC, De Carvalho L, Lopes-Bezerra LM, Morandi V. 2004. The in vitro interaction of Sporothrix schenckii with human endothelial cells is modulated by cytokines and involves endothelial surface molecules. Microb Pathog 36: 177-188.

Figueiredo CC, Deccache PM, Lopes-Bezerra LM, Morandi V. 2007. TGF- $\beta 1$ induces transendothelial migration of the pathogenic fungus Sporothrix schenckii by a paracellular route involving extracellular matrix proteins. Microbiology 153: 2910-2921.

Filler SG, Sheppard DC. 2006. Fungal invasion of normally non-phagocytic host cells. PLoS Pathog 2: e129.

Filler SG, Swerdloff JN, Hobbs C, Luckett PM. 1995. Penetration and damage of endothelial cells by Candida albicans. Infect Immun 63: 976-983.

Finkel-Jimenez B, Wuthrich M, Klein BS. 2002. BAD1, an essential virulence factor of Blastomyces dermatitidis, suppresses host TNF- $\alpha$ production through TGF- $\beta$-dependent and -independent mechanisms. J Immunol 168: 5746-5755.

Fontaine T, Delangle A, Simenel C, Coddeville B, van Vliet SJ, van Kooyk Y, Bozza S, Moretti S, Schwarz F, Trichot C, et al. 2011. Galactosaminogalactan, a new immunosuppressive polysaccharide of Aspergillus fumigatus. PLoS Pathog 7: e1002372.

Frank CF, Hostetter MK. 2007. Cleavage of E-cadherin: A mechanism for disruption of the intestinal epithelial barrier by Candida albicans. Transl Res 149: 211-222.

Fu Y, Phan QT, Luo G, Solis NV, Liu Y, Cormack BP, Edwards JE Jr, Ibrahim AS, Filler SG. 2013. Investigation of the function of Candida albicans Als3 by heterologous expression in Candida glabrata. Infect Immun 81: 25282535.

Garcia-Tamayo J, Castillo G, Martinez AJ. 1982. Human genital candidiasis: Histochemistry, scanning and transmission electron microscopy. Acta Cytol 26: 7-14.

Gebremariam T, Liu M, Luo G, Bruno V, Phan QT, Waring AJ, Edwards JE Jr, Filler SG, Yeaman MR, Ibrahim AS 2014. CotH3 mediates fungal invasion of host cells during mucormycosis. J Clin Invest 124: 237-250.

Gravelat FN, Ejzykowicz DE, Chiang LY, Chabot JC, Urb M, Macdonald KD, al-Bader N, Filler SG, Sheppard DC 2010. Aspergillus fumigatus MedA governs adherence, host cell interactions and virulence. Cell Microbiol 12: 473-488.

Gravelat FN, Beauvais A, Liu H, Lee MJ, Snarr BD, Chen D, Xu W, Kravtsov I, Hoareau CM, Vanier G, et al. 2013 Aspergillus galactosaminogalactan mediates adherence to host constituents and conceals hyphal $\beta$-glucan from the immune system. PLoS Pathog 9: e1003575.

Grubb SE, Murdoch C, Sudbery PE, Saville SP, Lopez-Ribot JL, Thornhill MH. 2008. Candida albicans-endothelial cell interactions: A key step in the pathogenesis of systemic candidiasis. Infect Immun 76: 4370-4377. 
Han X, Yu R, Zhen D, Tao S, Schmidt M, Han L. 2011. $\beta-1,3$ glucan-induced host phospholipase $\mathrm{D}$ activation is involved in Aspergillus fumigatus internalization into type II human pneumocyte A549 cells. PLoS ONE 6: e21468.

Hoyer LL, Payne TL, Bell M, Myers AM, Scherer S. 1998 Candida albicans ALS3 and insights into the nature of the ALS gene family. Curr Genet 33: 451-459.

Hoyte JS, Standing JE, Limper AH. 1997. Steady-state effects of vitronectin and fibronectin on the binding, uptake, and degradation of Pneumocystis carinii in rat alveolar macrophages. Inflammation 21: 335-345.

Huang SH, Long M, Wu CH, Kwon-Chung KJ, Chang YC, Chi F, Lee S, Jong A. 2011. Invasion of Cryptococcus neoformans into human brain microvascular endothelial cells is mediated through the lipid rafts-endocytic pathway via the dual specificity tyrosine phosphorylationregulated kinase 3 (DYRK3). J Biol Chem 286: 34761 34769.

Jong A, Wu CH, Chen HM, Luo F, Kwon-Chung KJ, Chang YC, Lamunyon CW, Plaas A, Huang SH. 2007. Identification and characterization of CPS1 as a hyaluronic acid synthase contributing to the pathogenesis of Cryptococcus neoformans infection. Eukaryot Cell 6: 1486-1496.

Jong A, Wu CH, Prasadarao NV, Kwon-Chung KJ, Chang YC, Ouyang Y, Shackleford GM, Huang SH. 2008a. Invasion of Cryptococcus neoformans into human brain microvascular endothelial cells requires protein kinase C- $\alpha$ activation. Cell Microbiol 10: 1854-1865.

Jong A, Wu CH, Shackleford GM, Kwon-Chung KJ, Chang YC, Chen HM, Ouyang Y, Huang SH. 2008b. Involvement of human CD44 during Cryptococcus neoformans infection of brain microvascular endothelial cells. Cell Microbiol 10: 1313-1326.

Jong A, Wu CH, Gonzales-Gomez I, Kwon-Chung KJ, Chang YC, Tseng HK, Cho WL, Huang SH. 2012. Hyaluronic acid receptor $\mathrm{CD} 44$ deficiency is associated with decreased Cryptococcus neoformans brain infection. J Biol Chem 287: 15298-15306.

Kamai Y, Kubota M, Hosokawa T, Fukuoka T, Filler SG. 2001. New model of oropharyngeal candidiasis in mice. Antimicrob Agents Chemother 45: 3195-3197.

Kamai Y, Lossinsky AS, Liu H, Sheppard DC, Filler SG. 2009. Polarized response of endothelial cells to invasion by $A s-$ pergillus fumigatus. Cell Microbiol 11: 170-182.

Klein BS, Hogan LH, Jones JM. 1993. Immunologic recognition of a 25-amino acid repeat arrayed in tandem on a major antigen of Blastomyces dermatitidis. J Clin Invest 92: $330-337$.

Krause W, Matheis H, Wulf K. 1969. Fungaemia and funguria after oral administration of Candida albicans. Lancet 1: $598-599$.

Kutty G, England KJ, Kovacs JA. 2013. Expression of Pneumocystis jirovecii major surface glycoprotein in Saccharomyces cerevisiae. J Infect Dis 208: 170-179.

Lee MJ, Gravelat FN, Cerone RP, Baptista SD, Campoli PV, Choe SI, Kravtsov I, Vinogradov E, Creuzenet C, Liu H, et al. 2013. Overlapping and distinct roles of Aspergillus fumigatus UDP-glucose 4-epimerases in galactose metabolism and the synthesis of galactose-containing cell wall polysaccharides. J Biol Chem 20: 1243-1256.

Levdansky E, Kashi O, Sharon H, Shadkchan Y, Osherov N. 2010. The Aspergillus fumigatus cspA gene encoding a repeat-rich cell wall protein is important for normal conidial cell wall architecture and interaction with host cells. Eukaryot Cell 9: 1403-1415.

Lima OC, Figueiredo CC, Previato JO, Mendonca-Previato L, Morandi V, Lopes Bezerra LM. 2001. Involvement of fungal cell wall components in adhesion of Sporothrix schenckii to human fibronectin. Infect Immun 69: 6874-6880.

Lima OC, Bouchara JP, Renier G, Marot-Leblond A, Chabasse D, Lopes-Bezerra LM. 2004. Immunofluorescence and flow cytometry analysis of fibronectin and laminin binding to Sporothrix schenckii yeast cells and conidia. Microb Pathog 37: 131-140.

Limper AH, Standing JE, Hoffman OA, Castro M, Neese LW. 1993. Vitronectin binds to Pneumocystis carinii and mediates organism attachment to cultured lung epithelial cells. Infect Immun 61: 4302-4309.

Limper AH, Thomas CF Jr, Anders RA, Leof EB. 1997. Interactions of parasite and host epithelial cell cycle regulation during Pneumocystis carinii pneumonia. J Lab Clin Med 130: 132-138.

Liu M, Spellberg B, Phan QT, Fu Y, Lee AS, Edwards JE Jr, Filler SG, Ibrahim AS. 2010. The endothelial cell receptor GRP78 is required for mucormycosis pathogenesis in diabetic mice. J Clin Invest 120: 1914-1924.

Liu Y, Mittal R, Solis NV, Prasadarao NV, Filler SG. 2011. Mechanisms of Candida albicans trafficking to the brain. PLoS Pathog 7: e1002305.

Liu TB, Kim JC, Wang Y, Toffaletti DL, Eugenin E, Perfect JR, Kim KJ, Xue C. 2013. Brain inositol is a novel stimulator for promoting Cryptococcus penetration of the bloodbrain barrier. PLoS Pathog 9: e1003247.

Liu Y, Solis NV, Heilmann CJ, Phan QT, Mitchell AP, Klis FM, Filler SG. 2014. Role of retrograde trafficking in stress response, host cell interactions, and virulence of Candida albicans. Eukaryot Cell 13: 279-287.

Long M, Huang SH, Wu CH, Shackleford GM, Jong A. 2012. Lipid raft/caveolae signaling is required for Cryptococcus neoformans invasion into human brain microvascular endothelial cells. J Biomed Sci 19: 19.

Lopes-Bezerra LM, Filler SG. 2004. Interactions of Aspergillus fumigatus with endothelial cells: Internalization, injury, and stimulation of tissue factor activity. Blood 103: 2143-2149.

Loussert C, Schmitt C, Prevost MC, Balloy V, Fadel E, Philippe B, Kauffmann-Lacroix C, Latgé JP, Beauvais A 2010. In vivo biofilm composition of Aspergillus fumigatus. Cell Microbiol 12: 405-410.

Mengaud J, Ohayon H, Gounon P, Mege RM, Cossart P. 1996. E-cadherin is the receptor for internalin, a surface protein required for entry of L. monocytogenes into epithelial cells. Cell 84: 923-932.

Montes LF, Wilborn WH. 1968. Ultrastructural features of host-parasite relationship in oral candidiasis. J Bacteriol 96: $1349-1356$.

Moreno-Ruiz E, Galan-Diez M, Zhu W, Fernandez-Ruiz E, D’Enfert C, Filler SG, Cossart P, Veiga E. 2009. Candida albicans internalization by host cells is mediated by a clathrin-dependent mechanism. Cell Microbiol 11: $1179-1189$. 
D.C. Sheppard and S.G. Filler

Newman SL, Chaturvedi S, Klein BS. 1995. The WI-1 antigen of Blastomyces dermatitidis yeasts mediates binding to human macrophage CD11b/CD18 (CR3) and CD14.J Immunol 154: 753-761.

Nolan DJ, Ginsberg M, Israely E, Palikuqi B, Poulos MG, James D, Ding BS, Schachterle W, Liu Y, Rosenwaks Z, et al. 2013. Molecular signatures of tissue-specific microvascular endothelial cell heterogeneity in organ maintenance and regeneration. Dev Cell 26: 204-219.

Olszewski MA, Noverr MC, Chen GH, Toews GB, Cox GM, Perfect JR, Huffnagle GB. 2004. Urease expression by Cryptococcus neoformans promotes microvascular sequestration, thereby enhancing central nervous system invasion. Am J Pathol 164: 1761-1771.

Paris S, Boisvieux-Ulrich E, Crestani B, Houcine O, Taramelli D, Lombardi L, Latgé JP. 1997. Internalization of Aspergillus fumigatus conidia by epithelial and endothelial cells. Infect Immun 65: 1510-1514.

Paris S, Debeaupuis JP, Crameri R, Carey M, Charles F, Prevost MC, Schmitt C, Philippe B, Latgé JP. 2003. Conidial hydrophobins of Aspergillus fumigatus. Appl Environ Microbiol 69: 1581-1588.

Park H, Myers CL, Sheppard DC, Phan QT, Sanchez AA, Edwards JE Jr, Filler SG. 2005. Role of the fungal Rasprotein kinase A pathway in governing epithelial cell interactions during oropharyngeal candidiasis. Cell Microbiol 7: 499-510.

Pfaller M, Neofytos D, Diekema D, Azie N, Meier-Kriesche HU, Quan SP, Horn D. 2012. Epidemiology and outcomes of candidemia in 3648 patients: Data from the Prospective Antifungal Therapy (PATH Alliance) registry, 2004-2008. Diagn Microbiol Infect Dis 74: 323-331.

Phan QT, Myers CL, Fu Y, Sheppard DC, Yeaman MR, Welch WH, Ibrahim AS, Edwards JE, Filler SG. 2007. Als3 is a Candida albicans invasin that binds to cadherins and induces endocytosis by host cells. PLoS Biol 5: e64.

Phan QT, Eng DK, Mostowy S, Park H, Cossart P, Filler SG. 2013. Role of endothelial cell septin 7 in the endocytosis of Candida albicans. mBio 4: 00542-00513.

Pottratz ST, Martin WJ II. 1990a. Mechanism of Pneumocystis carinii attachment to cultured rat alveolar macrophages. J Clin Invest 86: 1678-1683.

Pottratz ST, Martin WJ II. 1990b. Role of fibronectin in Pneumocystis carinii attachment to cultured lung cells. J Clin Invest 85: 351-356.

Pottratz ST, Paulsrud J, Smith JS, Martin WJ II. 1991. Pneumocystis carinii attachment to cultured lung cells by pneumocystis gp 120, a fibronectin binding protein. J Clin Invest 88: 403-407.

Pottratz ST, Paulsrud JR, Smith JS, Martin WJ II. 1994. Evidence for Pneumocystis carinii binding to a cell-free substrate: Role of the adhesive protein fibronectin. J Lab Clin Med 123: 273-281.

Pottratz ST, Reese S, Sheldon JL. 1998. Pneumocystis carinii induces interleukin 6 production by an alveolar epithelial cell line. Eur J Clin Invest 28: 424-429.

Quimby K, Lilly EA, Zacharek M, McNulty K, Leigh JE, Vazquez JE, Fidel PL Jr. 2012. CD8 T cells and E-cadherin in host responses against oropharyngeal candidiasis. Oral Dis 18: $153-161$.
Rajasingham KC, Challacombe SJ, Tovey S. 1989. Ultrastructure and possible processes involved in the invasion of host epithelial cells by Candida albicans in vaginal candidosis. Cytobios 60: 11-20.

Redding SW, Zellars RC, Kirkpatrick WR, McAtee RK, Caceres MA, Fothergill AW, Lopez-Ribot JL, Bailey CW, Rinaldi MG, Patterson TF. 1999. Epidemiology of oropharyngeal Candida colonization and infection in patients receiving radiation for head and neck cancer. J Clin $\mathrm{Mi}$ crobiol 37: 3896-3900.

Reichart PA, Philipsen HP, Schmidt-Westhausen A, Samaranayake LP. 1995. Pseudomembranous oral candidiasis in HIV infection: Ultrastructural findings. J Oral Pathol Med 24: $276-281$.

Richter SS, Galask RP, Messer SA, Hollis RJ, Diekema DJ, Pfaller MA. 2005. Antifungal susceptibilities of Candida species causing vulvovaginitis and epidemiology of recurrent cases. J Clin Microbiol 43: 2155-2162.

Rollenhagen C, Wollert T, Langford GM, Sundstrom P. 2009. Stimulation of cell motility and expression of late markers of differentiation in human oral keratinocytes by Candida albicans. Cell Microbiol 11: 946-966.

Rotrosen D, Edwards JE Jr, Gibson TR, Moore JC, Cohen AH, Green I. 1985. Adherence of Candida to cultured vascular endothelial cells: Mechanisms of attachment and endothelial cell penetration. J Infect Dis 152: 1264 1274.

Ruiz-Baca E, Toriello C, Perez-Torres A, Sabanero-Lopez M, Villagomez-Castro JC, Lopez-Romero E. 2009. Isolation and some properties of a glycoprotein of $70 \mathrm{kDa}(\mathrm{Gp} 70)$ from the cell wall of Sporothrix schenckii involved in fungal adherence to dermal extracellular matrix. Med Mycol 47: 185-196.

Sandoval-Bernal G, Barbosa-Sabanero G, Shibayama M, Perez-Torres A, Tsutsumi V, Sabanero M. 2011. Cell wall glycoproteins participate in the adhesion of Sporothrix schenckii to epithelial cells. Mycopathologia 171: 251259.

Scherwitz C. 1982. Ultrastructure of human cutaneous candidosis. J Invest Dermatol 78: 200-205.

Seidl K, Solis NV, Bayer AS, Hady WA, Ellison S, Klashman MC, Xiong YQ, Filler SG. 2012. Divergent responses of different endothelial cell types to infection with Candida albicans and Staphylococcus aureus. PLoS ONE 7: e39633.

Shi M, Li SS, Zheng C, Jones GJ, Kim KS, Zhou H, Kubes P, Mody CH. 2010. Real-time imaging of trapping and urease-dependent transmigration of Cryptococcus neoformans in mouse brain. J Clin Invest 120: 1683-1693.

Shintaku T, Glass KA, Hirakawa MP, Longley SJ, Bennett RJ, Bliss JM, Shaw SK. 2013. Human endothelial cells internalize Candida parapsilosis via N-WASP-mediated endocytosis. Infect Immun 81: 2777-2787.

Singh A, Panting RJ, Varma A, Saijo T, Waldron KJ, Jong A, Ngamskulrungroj P, Chang YC, Rutherford JC, KwonChung KJ. 2013. Factors required for activation of urease as a virulence determinant in Cryptococcus neoformans. mBio 4: e00220-00213.

Solis NV, Filler SG. 2012. Mouse model of oropharyngeal candidiasis. Nat Protoc 7: 637-642.

Stie J, Fox D. 2012a. Blood-brain barrier invasion by Cryptococcus neoformans is enhanced by functional interactions with plasmin. Microbiology 158: 240-258. 
Stie J, Fox D. 2012b. Induction of brain microvascular endothelial cell urokinase expression by Cryptococcus neoformans facilitates blood-brain barrier invasion. PLoS ONE 7: e49402.

Sun JN, Solis NV, Phan QT, Bajwa JS, Kashleva H, Thompson A, Liu Y, Dongari-Bagtzoglou A, Edgerton M, Filler SG. 2010. Host cell invasion and virulence mediated by Candida albicans Ssa1. PLoS Pathog 6: e1001181.

Teixeira PA, de Castro RA, Nascimento RC, Tronchin G, Torres AP, Lazera M, de Almeida SR, Bouchara JP, Loureiro y Penha CV, Lopes-Bezerra LM. 2009. Cell surface expression of adhesins for fibronectin correlates with virulence in Sporothrix schenckii. Microbiology 155: 37303738.

Thau N, Monod M, Crestani B, Rolland C, Tronchin G, Latgé JP, Paris S. 1994. rodletless mutants of Aspergillus fumigatus. Infect Immun 62: 4380-4388.

Upadhyay SK, Mahajan L, Ramjee S, Singh Y, Basir SF, Madan T. 2009. Identification and characterization of a laminin-binding protein of Aspergillus fumigatus: Extracellular thaumatin domain protein (AfCalAp). J Med Microbiol 58: 714-722.

Vaknin Y, Shadkchan Y, Levdansky E, Morozov M, Romano J, Osherov N. 2013. The three Aspergillus fumigatus CFEM-domain GPI-anchored proteins (CfmA-C) affect cell-wall stability but do not play a role in fungal virulence. Fungal Genet Biol 63: 55-64.

Vassallo R, Kottom TJ, Standing JE, Limper AH. 2001. Vitronectin and fibronectin function as glucan binding proteins augmenting macrophage responses to Pneumocystis carinii. Am J Respir Cell Mol Biol 25: 203-211.

Villar CC, Kashleva H, Nobile CJ, Mitchell AP, DongariBagtzoglou A. 2007. Mucosal tissue invasion by Candida albicans is associated with E-cadherin degradation, mediated by transcription factor Rim101p and protease Sap5p. Infect Immun 75: 2126-2135.

Wachtler B, Citiulo F, Jablonowski N, Forster S, Dalle F Schaller M, Wilson D, Hube B. 2012. Candida albicansepithelial interactions: Dissecting the roles of active penetration, induced endocytosis and host factors on the infection process. PLoS ONE 7: e36952.

Wang Y, Liu TB, Delmas G, Park S, Perlin D, Xue C. 2011. Two major inositol transporters and their role in cryptococcal virulence. Eukaryot Cell 10: 618-628.

Wang L, Zhai B, Lin X. 2012. The link between morphotype transition and virulence in Cryptococcus neoformans. PLoS Pathog 8: e1002765.

Wang L, Tian X, Gyawali R, Lin X. 2013. Fungal adhesion protein guides community behaviors and autoinduction in a paracrine manner. Proc Natl Acad Sci 110: 1157111576.

Wasylnka JA, Moore MM. 2002. Uptake of Aspergillus fumigatus conidia by phagocytic and nonphagocytic cells in vitro: Quantitation using strains expressing green fluorescent protein. Infect Immun 70: 3156-3163.

Wasylnka JA, Moore MM. 2003. Aspergillus fumigatus conidia survive and germinate in acidic organelles of A549 epithelial cells. J Cell Sci 116: 1579-1587.

Wasylnka JA, Simmer MI, Moore MM. 2001. Differences in sialic acid density in pathogenic and non-pathogenic Aspergillus species. Microbiology 147: 869-877.

Wasylnka JA, Hissen AH, Wan AN, Moore MM. 2005. Intracellular and extracellular growth of Aspergillus fumigatus. Med Mycol 43: S27-S30.

Willis AM, Coulter WA, Fulton CR, Hayes JR, Bell PM, Lamey PJ. 1999. Oral candidal carriage and infection in insulin-treated diabetic patients. Diabet Med 16: 675679.

Wuthrich M, Finkel-Jimenez B, Brandhorst TT, Filutowicz HI, Warner T, Klein BS. 2006. Analysis of non-adhesive pathogenic mechanisms of BAD1 on Blastomyces dermatitidis. Med Mycol 44: 41-49.

Xu XY, Shi Y, Zhang PP, Shen YY, Zhang F, Song Y. 2010. $\mathrm{N}$-cadherin as a receptor for adhesion and endocytosis of Aspergillus fumigatus by human umbilical vein endothelial cells. Zhonghua Jie He He Hu Xi Za Zhi 33: 734-737.

Xu XY, Shi Y, Zhang PP, Zhang F, Shen YY, Su X, Zhao BL. 2012. E-cadherin mediates adhesion and endocytosis of Aspergillus fumigatus blastospores in human epithelial cells. Chin Med J 125: 617-621.

Yong SJ, Vuk-Pavlovic Z, Standing JE, Crouch EC, Limper AH. 2003. Surfactant protein D-mediated aggregation of Pneumocystis carinii impairs phagocytosis by alveolar macrophages. Infect Immun 71: 1662-1671.

Zakikhany K, Naglik JR, Schmidt-Westhausen A, Holland G, Schaller M, Hube B. 2007. In vivo transcript profiling of Candida albicans identifies a gene essential for interepithelial dissemination. Cell Microbiol 9: 2938-2954.

Zhu W, Filler SG. 2010. Interactions of Candida albicans with epithelial cells. Cell Microbiol 12: 273-282.

Zhu W, Phan QT, Boontheung P, Solis NV, Loo JA, Filler SG. 2012. EGFR and HER2 receptor kinase signaling mediate epithelial cell invasion by Candida albicans during oropharyngeal infection. Proc Natl Acad Sci 109: $14194-$ 14199 . 


\section{$\&_{\mathrm{CSH}}^{\infty} \&$ Cold Spring Harbor

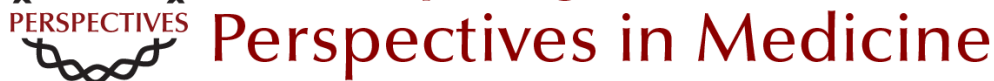

\section{Host Cell Invasion by Medically Important Fungi}

Donald C. Sheppard and Scott G. Filler

Cold Spring Harb Perspect Med 2015; doi: 10.1101/cshperspect.a019687 originally published online November 3, 2014

Subject Collection Human Fungal Pathogens

\section{Evolutionary Perspectives on Human Fungal Pathogens John W. Taylor}

Black Molds and Melanized Yeasts Pathogenic to Humans Anuradha Chowdhary, John Perfect and G. Sybren de Hoog

Fungal Pathogens: Survival and Replication within Macrophages Andrew S. Gilbert, Robert T. Wheeler and Robin C. May

Innate Defense against Fungal Pathogens Rebecca A. Drummond, Sarah L. Gaffen, Amy G. Hise, et al.

Antifungal Pharmacokinetics and Pharmacodynamics Alexander J. Lepak and David R. Andes

Human Fungal Pathogens of Mucorales and Entomophthorales

Leonel Mendoza, Raquel Vilela, Kerstin Voelz, et al.

Functional Profiling of Human Fungal Pathogen Genomes

Alexi I. Goranov and Hiten D. Madhani

Aspergillus fumigatus and Related Species Janyce A. Sugui, Kyung J. Kwon-Chung, Praveen R. Juvvadi, et al.
Thermally Dimorphic Human Fungal Pathogens-Polyphyletic Pathogens with a Convergent

Pathogenicity Trait Anita Sil and Alex Andrianopoulos

Mechanisms of Antifungal Drug Resistance Leah E. Cowen, Dominique Sanglard, Susan J. Howard, et al.

Treatment Principles for Candida and Cryptococcus Laura C. Whitney and Tihana Bicanic

The Human Mycobiome Patrick C. Seed

Treatment Principles for the Management of Mold Infections

Dimitrios P. Kontoyiannis and Russell E. Lewis

Adaptive Immunity to Fungi Akash Verma, Marcel Wüthrich, George Deepe, et al.

The Candida Pathogenic Species Complex Siobhán A. Turner and Geraldine Butler

Fungal Morphogenesis Xiaorong Lin, J. Andrew Alspaugh, Haoping Liu, et al.

For additional articles in this collection, see http://perspectivesinmedicine.cshlp.org/cgi/collection/ 